\title{
Harmonization in the EAC
}

\author{
Aleem Tharani
}

\subsection{Introduction}

Regional integration is a major development strategy for African countries who share the aim of continent-wide economic, social and cultural integration by 2028. An important aspect of this is trade liberalization. This is to be achieved through regional free trade areas, progressing towards a customs union, a common market and ultimately monetary union. The East African Community (EAC) is a regional intergovernmental organisation of five Partner States, comprising Burundi, Kenya, Rwanda, Tanzania and Uganda (the Partner States), headquartered in Arusha, Tanzania. The broad goal of the EAC is to widen and deepen cooperation among the Partner States. The EAC is one of eight regional economic communities recognised by the African Union (AU), and the only one that has a vision of the creation of a political federation within the EAC. This Chapter will look at how the EAC can use harmonisation to further integration by focusing on the energy sector.

It is well established that Africa is rich in resources, however, has poor infrastructure. In the energy sector, while the EAC is focused on laying the groundwork to ensure that energy and power are harnessed by all Partner States, what additionally will need to be harnessed is regional integration and the harmonisation not only of policy but of laws. Harmonization is necessary in order to ensure that within the EAC, no deterrent Partner States that have not been on the strongest footing in terms of legislation and those Partner States traditionally regarded as "legally safe" are both regarded equally.

\subsection{The Rationale for Harmonization}

There can be little doubt that the increase in inter-state trade promotes economic development and growth. In order to further economic growth, developed and developing countries alike have entered into relationships characterised by interdependence. This interdependence has prompted a move towards economic convergence and this is where the idea of regionalism originates; it is rooted in the observation that small and fragmented markets 
hamper economic development and trade, and that economic development is measured, inter alia, by the ability of a country to create a good environment for the private sector. Regional integration arrangements are intended to pave the way towards the creation of larger regional markets. A larger market benefits the participating countries in that it enhances domestic competition, encourages economic diversification, increases return on investment, thereby attracting more investment.

Evidence from the harmonization of energy laws in other trade communities globally suggests that harmonization results in increased efficiency and approvals for the energy sector thereby cutting one or two years off the overall approval process (thereby allowing project development to occur quicker) and enhancing domestic GDP by upwards of $8 \%-10 \%$.

There is a tremendous variation across East Africa in the legal framework and policy when the fundamentals of the energy industry and how a developer goes about exploration, project development, operations and decommissioning are considered. These variations, combined with the economic consequences of mismanagement of the sector create investment uncertainty. This investment uncertainty is increased by "inefficient and cumbersome" legislation found in some East African States. Even if a potential investor (and a potential trader for that matter) is not deterred by the unfamiliarity or possible complexity of a foreign legal system, he may be loathed to invest in a state whose laws have not been brought up to date with the developments in economic and international relations. Of course, once attracted, investor interests must be protected and each African state must have laws that provide such security to all investors.

Harmonization is also important to deal with global transboundary issues such as climate change. Climate change resulting from energy-related greenhouse gas emissions is a global challenge without physical or geographical borders which pose various threats to vulnerable regions such as the EAC. The transboundary nature of climate change and its effects necessitates regulatory action in the form of harmonized law and policy responses among the EAC Partner States. The role of the energy sector in climate change mitigation in developing regions such as the EAC pertains to a shift from overtly fossil fuelbased energy sectors to more renewable energy sources. The energy sector reforms needed to achieve this transition to a low carbon economy based on less carbon-intensive energy sources should be regulated in terms of harmonized sub-regional law and policy.

Many African countries already have institutions, legislations and regulations which allowed interconnection and electricity market. Benchmark national legislation and best practices identified represent good examples for 
less advanced countries, regarding the different framework conditions, for cooperation and harmonization. The power sector of the Sub-Saharan countries, with the exception of South Africa, is comprised of relatively small systems which are characterized by technical, operational and financial problems. The creation of regional markets is essential for creating the environment to attract the needed (funds) capital, technology and expertise to help fix the challenges of the electricity deficit. Many countries under perform in rate and level of electricity access, because of weak means and also due to a lack of policies, poor enabling environment for private sector investments, and institutions for development and roll-out of related programmes, in particular through innovative ways, including renewable energy and mini-grid solutions. Despite a large number of best practices, there are a range of remaining barriers hindering the development and access to modern and sustainable energy services on the continent, including: low levels and lack of effective policy, regulatory and institutional frameworks; unattractive energy market to potential investors due to high investment costs and low technical skills and implementation capacity, amongst others.

Harmonization is not only a public sector led initiative. The role of the private sector in African regional integration (which has to date been largely in the hands of governments and non-governmental organisations) is gradually increasing. Apart from its contribution to policymaking and advice to governments, the private sector can participate in the implementation of regional projects and provide financial and human resources, spread of expertise, and technological and management knowledge. It can also contribute to production of goods, job creation and increased market size and crossborder investment. The harmonization of legal regimes improves the capacity of states to coordinate their economic policies. If harmonization of laws is extended beyond the coordination of economic policies to include substantive business laws among Partner States, individual traders will be encouraged, but so will potential investors who will have the needed assurance that they will be familiar with the legal procedure and consequences. Every investor, creditor or trader wants to be aware of the risks inherent in the undertaken commercial transaction. Where the content and effect of legal rights and obligations are more predictable, the legal risks and thus the transaction costs are reduced.

Regional harmonization is a necessary corollary to the overall aim to promote trade and investment and increase economic growth. In order to make the process of regional integration meaningful, traders and investors must be given the opportunity to avoid the doldrums of legal diversity, they must 
be allowed to rely on laws which are in line with the realities of business practice and which are up to date with international standards. This should involve the harmonization of domestic substantive legal provisions. What remains for East African states is to find the most appropriate method by which such harmonization would take place.

\subsection{EAC Approach to Integration and Harmonization in the Energy Sector}

Co-operation in the energy sector among the Partner States is governed by Article 101 of the Treaty for the Establishment of the East African Community (the Treaty).

Article 101 of the Treaty provides that the Partner States shall adopt policies and mechanisms to promote the efficient exploitation, development, joint research and utilisation of various energy resources available within the region and shall in particular promote within the Community:

1. the least cost development and transmission of electric power, efficient exploration and exploitation of fossil fuels and utilisation of new and renewable energy sources;

2. the joint planning, training and research in, and the exchange of information on the exploration, exploitation, development and utilisation of available energy resources,

3. the development of integrated policy on rural electrification,

4. the development of inter-Partner State electrical grid interconnections,

5. the construction of oil and gas pipelines, and

6. all such other measures to supply affordable energy to their people taking cognisance of the protection of the environment as provided for by this Treaty.

In order to achieve the Article 101 objectives, the sector has been organised into three sub-sectors, namely:

1. Power (including transmission and interconnectivity);

2. New and Renewable Energy Sources, Energy Conservation and Energy Efficiency; and

3. Fossil fuels. 


\subsubsection{The Power Sector}

The following have been identified as the key harmonization objectives for the Power sub-sector:

1. Cooperation on power sector issues of regional interest;

2. Development of regional interconnections;

3. Joint development of power projects for regional benefit;

4. Development of regional power markets; and

5. Exchange of technical and strategic information.

In order to foster power system interconnectivity by the Heads of States of the Common Market for Eastern and Southern Africa (COMESA) region, a specialised institution named the Eastern Africa Power Pool (the EAPP) was established in 2005 with the signing of an Inter-Governmental Memorandum of Understanding (IGMOU) by seven Eastern Africa countries, namely: Burundi, Democratic Republic of Congo (DRC), Egypt, Ethiopia, Kenya, Rwanda and Sudan. Since the IGMou, Tanzania, Libya and Uganda have also joined the EAPP.

The main objective of the EAPP is the optimum development of energy resources in the region and to ease the access to electricity power supply to all people of the countries in the Eastern Africa region through regional power interconnections. The EAPP has also been formed to achieve the following goals:

1. To be a framework for pooling energy resources, promoting power exchanges between utilities in Eastern Africa and reduce power supply costs based on an integrated master plan and pre-established rules (Grid code);

2. Optimize the usage of energy resources available in the region by working out regional investment schemes in Power Generation, Transmission and Distribution;

3. Reduce electricity cost in the region by using power systems interconnection and increasing power exchanges between countries; and

4. Provide efficient co-ordination between various initiatives taken in the fields of power production, transmission as well as exchanges in the region.

Well on its ways to achieving its objectives, the EAPP has so far: 
1. Together with the EAC, developed a Regional Power Master Plan and Interconnection Code that will allow the EAC and EAPP to identify sources of cheap electricity from ten Eastern Africa countries that the EAC could use to interconnect to and complement the development of locally available resources; and

2. Developed a gap analysis tool to assist member country power utility companies to assess their compliance to the Interconnection Code. This is useful to member countries because the complete interconnectivity of the East African region is scheduled for the end of 2017 and in readiness for this, all power utility companies in the EAC and are working closely to be fully compliant to the Interconnection Code.

In addition to the work of the EAPP, the EAC works closely with other regional organisations in promoting regional projects and programmes. The aim of these projects, as with the EAPP is regional interconnection through the establishment of transmission lines in order to facilitate a vibrant regional power trade. In this regard, the EAC energy department works closely with the Nile Equatorial Lakes Subsidiary Action Programme, the Eastern Africa Power Pool, the Energy for Great Lakes and neighbouring Regional Economic Communities in collaboration with development partners.

One additional initiative of the EAC worth mentioning is the development of a cross-border electrification programme. This programme enables border towns to connect from the neighbouring Partner State at the distribution voltage when it is more economical than connecting with the grid within its own country. This initiative hopes to increase access in a cost effective manner. The EAC Cross-Border Electrification Policy governs the implementation of this programme as well as development of shared renewable energy resources such as small hydro power projects.

\subsubsection{Renewable Energy}

The objective of the EAC for the New and Renewable Energy Sources, Energy Conservation and Energy Efficiency sub-sector is to increase the deployment of renewable energy and the adoption of energy conservation and energy efficiency practices. Specific objectives include:

1. To promote development of New and Renewable Energy Sources;

2. To initiate programmes on Energy Conservation and Energy Efficiency; 
3. To develop a comprehensive energy conservation and efficiency strategy and plan; and

4. To develop a Renewable Energy Master Plan.

The following initiatives have been adopted to meet the above objectives:

1. Regional Strategy on Scaling-Up Access to Modern Energy Services

2. Technical Capacity Building for Small Hydropower projects

3. Establishment of the East Africa Centre for Renewable Energy and Energy Efficiency

To achieve its objectives and contribute towards increased access to modern, affordable and reliable energy services, in March 2014, the Sectoral Council on Energy approved the Project Document for the Establishment of the EAC Centre for Renewable Energy and Energy Efficiency (EACREEE). EACREEE is expected to be operational by end of 2016 .

\subsubsection{Fossil Fuels}

In order to facilitate the provision of efficient and reliable delivery of oil products throughout the region, a Regional Strategy on development of regional refineries was developed. It addresses all aspects of petroleum distribution systems in the region, including refineries and storage facilities in a holistic way in order to improve its effectiveness and efficiency. The Strategy reveals the clear interdependence between various forms of infrastructure in the delivery of petroleum products. Key recommendations for the strategy include:

1. The development a new refinery in Uganda in order for the oil already discovered in Uganda to benefit the region financially;

2. The acceleration of planned upgrading of the Mombasa refinery; and

3. The improvement in the handling, transportation, storage and distribution facilities in the region for efficient and economic distribution of petroleum products.

Important discoveries made in Kenya, Tanzania and Uganda are expected to enhance the resource potential for the region towards energy self-sufficiency. This has resulted in the scaling up of regional exploration efforts in the oil and gas sector.

The EAC has identified priority oil and gas pipeline projects as follows: 
1. Crude oil pipeline: Feasibility studies for a crude oil pipeline to transport crude oil from the Albertine Graben to the Indian Ocean for export have been completed. In addition, networks of crude oil pipelines which will transport crude oil from oil fields in the EAC to the refinery are currently under development. Also in development is an oil products pipeline from the refinery to Kampala, Uganda which will facilitate delivery to the market.

2. Upgrading existing oil products pipeline: The existing pipeline system runs from the Mombasa port to Eldoret and Kisumu in Western Kenya. The upgrade project covers construction of a new pipeline from Mombasa to Nairobi and between Sinendat and Kisumu as capacity enhancement for the Eldoret depot. These projects will contribute to planned expansion to other EAC Partner States and other countries that rely on the region for their petroleum imports. Further information on the development of the pipeline can be found on the Kenya Power (K PLC) website.

3. Kenya-Uganda-Rwanda-Burundi oil products pipeline: Feasibility studies and tender documents for the extension of the existing oil products pipeline from Kenya to Uganda and Rwanda have been completed and resources for E PC contracting are being mobilised. Procurement for consultancy services to carry out feasibility study for extension from Rwanda to Burundi is ongoing. The project sections include Eldoret (Kenya)—Kampala (Uganda), KampalaKigali (Rwanda) and Kigali—Bujumbura (Burundi). In addition, an oil products pipeline will link a new refinery in Hoima (Uganda) to Kampala making it a hub for refined oil products from the discoveries in the Albertine Graben for distribution in the region through the planned pipeline network. These projects will facilitate efficient, safe, cost-effective and environmentally-friendly distribution of the oil products.

4. Proposed Uganda-Tanzania oil products pipeline: EAC plans to link all its Partner States to the planned refinery development in Hoima, Uganda. It is in this context that an oil products pipeline is planned from Mbarara (Uganda) to Mwanza, Isaka and Dar es Salaam (Tanzania). The planned pipeline system from Kampala (Uganda) to Kigali (Rwanda) and Bujumbura (Burundi) will create a major depot in Mbarara (Uganda). The planned pipeline to Tanzania is proposed to start from this depot. Resources are being mobilised to carry out a feasibility study on the project. 


\subsection{Harmonisation in the Energy Sector from an EAC Perspective: Progress and Challenges}

The EAC faces several challenges in achieving its development vision. Energy has been recognised as one of the key elements in achieving this vision. Lack of electrical and motive power means that a majority of the population cannot participate in economic and social activities to improve their standards of living. Access to clean, affordable, and reliable energy has a profound bearing on living standards and human wellbeing. It is therefore necessary to move away from the 'business-as-usual' scenario to a more determined energy services driven approach that addresses some of the key barriers that hinder increased access to modern energy services.

An argument has also been made in favour of EAC Partner States entering into a multi-lateral investment treaty with a focus on trade and investment in energy. A number of factors combine in varying degrees to make a cooperative approach toward the harnessing of resources (and, therefore, policies) for sustainable energy development in the EAC. These include the underdevelopment and uneven distribution of energy resources across the region; the landlocked position of Uganda, Rwanda and Burundi and the consequent difficulties of importing commercial energy; the poverty of the consumers and a small sized market; the poor development of commercial energy infrastructure; and the lack of skilled technical expertise in the region. The guiding principles for investment regulation/liberalization towards a regional investment agreement for the EAC can be similar to those of the OECD's multilateral agreement, which have been described as follows: (1) Promoting a more secure, predictable, and transparent environment in which to plan and operate cross-border investments; (2) Ensuring greater protection for investors and their investments; (3) Promoting the progressive liberalization of barriers restricting the entry and conduct of foreign firms in domestic markets; (4) Reducing or eliminating measures that distort trade and investment decisions and reduce allocative efficiency; (5) Developing credible institutions and rules for solving potential disputes; (6) Ensuring adequate consideration for environmental issues, core labour standards and other related issues; and (7) Ensuring that the relationship between the agreement and other related international instruments is clarified. By providing greater predictability, transparency and legal security for investors, a regional investment agreement would have the added benefit of attracting more foreign direct investment in the region.

Although some progress has been made in achieving harmonisation, substantial challenges remain which are not specific to the energy sector. These include: 
1. The original EAC is a regional intergovernmental organisation that dates back to 1917 and collapsed in 1977 due to various political and economic reasons. The present EAC was established in 2000 with the aim of become an economic area (including customs and monetary unions, with harmonized macroeconomic policies, and ultimately a political federation). However, no overall timetable has been established for this process. EAc Partner States are yet to fully implement some of the provisions within the legal framework of the EAC, such as the harmonization of customs procedures, other duties and charges on imports, internal indirect taxes and fees on production.

2. Differences in implementation capacity among the various EAC Partner States has also affected the ability to fully implement the EAC Treaty into national law.

3. Membership in multiple trade agreements has also proved problematic from a harmonization and integration perspective. Kenya, Tanzania and Uganda participate in different regional trade agreements. For instance, Kenya and Uganda are members of the COMESA while Tanzania is a member of the Southern African Development Community (SADC) and a signatory to the Agreement on the Global System of Trade Preferences among Developing Countries (GSTP). Tanzania is also considering re-entering COMESA after its withdrawal in 2000. While each country is free under the provisions of the EAC to negotiate bilateral agreements provided they notify the other two members, in practice, overlapping membership has created problems. For instance, the agreements use different types of rules of origin, i.e. the criteria used to define where a product was made to determine whether it is eligible to benefit from liberalised trade within a regional trade agreement. The terms of entry of goods into the EAC can also vary for different importing countries since SADC and COMESA are governed by different protocols of trade.

From an energy sector perspective, the following observations can be made around harmonisation and integration:

1. EAC Partner States have more or less the same development and energy needs, with few disparities in the levels of each. What is required to achieve sustainable development in one country is not very different from what is required in another. For energy supply to be dependable enough to foster sustainable economic development 
in the EAC, there should be an effective and unified energy policy in place. This is lacking in the EAC. Each country has its own approaches to energy trade and investment. These, however, are neither effective nor uniform. Each country operates alone and the results do not promote economic development. It is of paramount importance, therefore, that the EAC puts in place a viable and harmonized energy policy, which will address the problems of trade and investment in sustainable energy. Harmonized and well thought out strategies will go a long way to promote sustainable development in the EAC

2. There is a further need amongst the EAC Partner States to harmonize the investment climate in the energy sector and thereby promote foreign investment in the energy sector. Measures are required to be taken in respect of expanding and upgrading the energy infrastructure; promoting energy efficiency and conservation; mobilising requisite financial resources for the operation and expansion of energy services consistent with rising demands; ensuring security of supply through diversification of sources and mixes in a cost effective manner; increasing accessibility to all sectors of the population; and improving corporate governance and accountability.

3. The divergence in energy related policies across the EAC has resulted in different standards of bankability being applied across the EAC Partner States thereby requiring investors to undertake detailed due diligence in respect of various issues across the EAC Partner States. The impact of this is that invariably, investors end up favouring one jurisdiction over another for purposes of investing in different segments of the energy sector. An example of such varying bankability thresholds is nowhere more evident than in the power sector. The potential of the power sector to be the driving force behind economic growth for each EAC Partner State cannot be disputed. The Eastern Africa region has more than 15,00oMW of geothermal power potential, located primarily in the Rift Valley areas. The untapped energy potential for the latter is estimated at more than 7,00oMW of electric power. Notwithstanding this, geothermal energy is currently under-exploited due to a number of challenges, including: (i) lack of an enabling policy, legal and regulatory framework that would attract investment into the region; (ii) colossal start-up investment outlays for geothermal exploration and development; and (iii) risks inherent with resource 
exploration and power development projects. In terms of the disparity between EAC Partner States in harnessing and exploiting this potential one need only look at the varying fortunes of the national offtakers in Kenya and Tanzania. The electricity sector in Tanzania is dominated by the Tanzania Electric Supply Company Limited (TANESCO) in a vertically integrated market structure carrying out generation, transmission, distribution and supply. In 1992, the Tanzania National Energy Policy ended the monopoly held by the public utility and allowed private sector involvement in the electricity industry. Although opportunities for economic growth are created by Tanzania's approximately US $\$ 75$ billion gas reserves, it is widely accepted that any TANESCO power purchase agreement (PPA) may be difficult to bank and any greenfield independent power producer (IPP) project will need government support in the form of a sovereign guarantee for all TANESCO payments under the PPA. By contrast, the Kenyan IPP market, which was unbundled in the mid-20oos, has largely moved away from any requirement for a government guarantee to backstop offtaker payments under the PPA. KPLC's ability to build this internal capacity and balance sheet strength is largely seen to have resulted from the 2007 unbundling. Besides being responsible for system operations, KPLC was mandated to prepare long-term generation plans (under the supervision of the regulator) and to procure new generation capacity from either Kenya Electricity (KenGen) or IPPs. Initially, KPLC relied on transaction advisers but has over time become an effective independent entity capable of running competitive international tenders and negotiating contracts with winning bidders.

4. Notwithstanding point 3 above, there are areas of common difficulties experienced amongst the EAC Partner States. Several studies have concluded that the biggest impediment to regional and intraAfrica trade is poor infrastructure, both in terms of missing links in existing regional networks and inadequate maintenance of existing infrastructure. The supply-side constraints include poor transport infrastructure, logistical problems, energy deficit, poor access to ICT, and water scarcity. Sustainable infrastructure will help remove those constraints and enhance trade. The focus on infrastructure is also consistent with continental initiatives. The financing needs of infrastructure development in Africa are huge. For example, weak power transmission and distribution infrastructure is due to limited 
investments in power system upgrading. The economies, therefore, experience high electrical power system losses, extreme voltage fluctuations and intermittent power outages that cause equipment and material damage and losses in production. The low level of electricity access explains the need for sustainable energy investment projects. The energy policies and legislation for EAC countries are supposed to respond to these challenges. Yet, much as these policies and legislation have been in place for some time, the challenges continue. To achieve sustainable development, the strong points of each policy, strategy and law should be put together and weak points dropped, to form a single unified energy policy, as well as strategies and legislation for the EAC.

The disparity in investment terms is also evident in the oil and gas sector where no EAC model form exploration law or production sharing agreement has been put into place. The existing upstream exploration regime between EAC Partner States differs significantly. For example:

each jurisdiction applies differing models in respect of matters such as signature bonuses, royalties as well as the applicable formula for production sharing;

differing rates of income tax apply to contractors across the different jurisdictions (Kenya: The income tax rate for branches is $37.5 \%$ (rather than $30 \%$ for resident companies); Tanzania: $10 \%$ of profits deemed to be repatriated; and Uganda: $15 \%$ of profits deemed to be repatriated); and

each country also applies different requirements in respect of local content requirements in the extractives industry.

\subsection{Conclusion}

The benefits of a regional approach to energy access have been well articulated. The potential economic benefits of a harmonized approach to legislation in this sector can have a domino effect that results in greater and large investments, which then results in positive economic benefits, which in turn has the potential to lead to better regulation, increased monitoring especially of environmental impacts and greater ownership by Partner States in the future of resources that they have been privileged to be entrusted with. 


\section{References}

African Development Bank-Eastern Africa Regional Integration Strategy Paper 2011-2015.

EAC Annual Report 2013-2014.

http://www.eac.int/energy/index.php?option=com_content\&view=article\&id=107\&It emid $=68$.

http://www.tralac.org/.

http://eappool.org/.

Regional Strategy on Scaling-up Access to Modern Energy Services-EAC.

Similar Solutions for Similar Problems: Harmonising Energy Trade and Investment Policies and Strategies in the East African Community-Kikonyogo (2009).

The need to harmonise trade-related laws within countries of the African Union: an introduction to the problems posed by legal divergence-Polina Dlagnekova (2012).

World Trade Organization-East African Community—-trade policy review report by the secretariat. 